\title{
Genetic alterations after carbon ion irradiation in human lung adenocarcinoma cells
}

\author{
EMMANOUIL FOKAS* ${ }^{*}$ AN YOU*, JANKO JURICKO, RITA ENGENHART-CABILLIC and HAN-XIANG AN \\ Department of Radiotherapy and Radiation Oncology, Philipps University Marburg, \\ Baldingerstrasse, 35043 Marburg, Germany
}

Received August 3, 2010; Accepted September 30, 2010

DOI: 10.3892/ijo_00000835

\begin{abstract}
The aim of this study was to investigate the difference in gene expression profiles of human lung adenocarcinoma cells and identify genes whose expression is altered by heavy ions but not X-rays. The lung adenocarcinoma cell line A549 was irradiated with carbon ion beams and $\mathrm{X}$-rays using biologically equivalent doses (2 Gy and $6 \mathrm{~Gy}$, respectively). The transcriptional profiling was determined with a high density cDNA microarray containing 11.800 genes, and genetic network and gene ontology analysis was performed. The changes in selected genes involved were validated by quantitative real-time polymerase chain reaction (qRT-PCR). The microarray analysis identified 49 mapped, network-eligible genes, the expression level of which was altered by carbon ions but not by X-rays. From these, 29 were upregulated while 20 genes were downregulated 4 h postirradiation with carbon ions in A549 cells, as compared to the control. Among these, three genes (CCND2, RARG and E2F5) were involved in the aryl hydrocarbon receptor signalling and G1/S cell cycle checkpoint pathways. The microarray data were corroborated by qRT-PCR analysis of the selected genes $(\mathrm{p}<0.05)$. Our findings provide information on the genetic signature of carbon ions in human lung adenocarcinoma cells and add to the understanding of the complicated molecular response to carbon ion irradiation.
\end{abstract}

\section{Introduction}

Lung cancer is the most common malignancy and the major cause of cancer-related deaths of men in industrialized countries (1). Conventional radiotherapy consists an effective modality for several human cancers $(2,3)$. However, a dose escalation

Correspondence to: Dr Han-Xiang An, Department of Radiotherapy and Radiation Oncology, Philipps-University Marburg, Baldingerstrasse, 35043 Marburg, Germany

E-mail: an@med.uni-marburg.de

${ }^{*}$ Contributed equally

Key words: carbon ions, human lung adenocarcinoma, microarray, gene ontology is often imperative to improve therapeutic outcome, with the cost of increased toxicity (4).

The superior biophysical and biological profiles of particle beams such as carbon beam and protons with excellent dose localization and sparing of normal tissues makes them highly attractive for treating malignant tumors including lung cancer, whereas more research is currently warranted to better evaluate the cost-effectiveness of particle therapy (5-8). The phase I and II clinical trials on carbon ion radiotherapy for stage I non-small cell lung cancer (NSCLC) have showed promising results regarding local control and overall survival $(5,6)$. A recent meta-analysis, though, concluded that survival rates for particle therapy were higher than those for conventional radiotherapy, but similar to sterotactic body radiotherapy in stage I inoperable NSCLC, suggesting that particle therapy may be more beneficial in stage III NSCLC, especially in reducing adverse events (8).

Despite the advance in understanding the radiobiological aspects of carbon ions (C12), their molecular mechanisms remain largely unknown. cDNA microarray technology is an effective tool to analyze transcriptional genetic alterations in response radiation (9). Recent microarray studies demonstrated different expression pattern in squamous cell carcinomaderived cells, melanomas and breast epithelial cell irradiated with C12 and X-rays (10-13).

We investigated the global expression changes of A549 human lung adenocarcinoma cell line after irradiation with C12 and X-rays by using high-density cDNA microarray containing 11.800 unique genes and transcripts. A comprehensive network and gene ontology analysis was performed using the Ingenuity Pathway Analysis tool (IPA) to identify networks of interacting genes and their corresponding canonical pathways. Our primary aim was to study the difference of gene expression between carbon ions and Xrays in human lung adenocarcinoma cells and identify genes which are differentially expressed by heavy ion irradiation and not substantially altered by X-rays.

\section{Materials and methods}

Cell line and culture condition. The human lung adenocarcinoma cell line A549 was obtained from American Type Culture Collection (Rockville, MD) and maintained in RPMI medium supplemented with $10 \%$ fetal calf serum and $1 \%$ penicillin, streptomycin (Sigma, Germany) at $37^{\circ} \mathrm{C}$ in $5 \% \mathrm{CO}_{2}$. 
Table I. Primers used for qRT-PCR of genes with altered expression after carbon ion irradiation.

\begin{tabular}{llll}
\hline Gene & \multicolumn{1}{c}{ Forward } & \multicolumn{1}{c}{ Reverse } & Size (bp) \\
\hline RARG & TACCACTATGGGGTCAGC & CCGGTCATTTCGCACAGCT & 195 \\
CCND2 & TGGAGCTGCTGTGCCACG & GTGGCCACCATTCTGCGC & 181 \\
E2F5 & TCAGGCACCTTCTGGTACAC & GGGCTTAGATGAACTCGACTC & 145 \\
CDC14B & GTGCCATTGCAGTACATT & AGCAGGCTATCAGAGTG & 123 \\
GAPDH & CATCTCTGCCCCCTCTGCTGA & GGATGACCTTGCCCACAGCCT & 305 \\
\hline
\end{tabular}

Bp, base pair.

Table II. Merged genetic networks identified in A549 cells irradiated with carbon ions.

\begin{tabular}{lll}
\hline Network & Gene & Function $^{\text {Score }}$ \\
\hline
\end{tabular}

1 Calmodulin, $\underline{\text { CAMK1D }}$, CASP8AP2, $\underline{\text { CCND2 }}, \underline{\text { CD70 }}$, FAS, DDB2, FAIM,

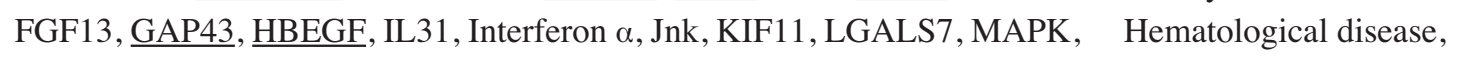
NCOA7, NFkB, NRIP2, NUAK2, P38 MAPK, PI3K, PKMYT1, PPM1D, Gastrointestinal disease

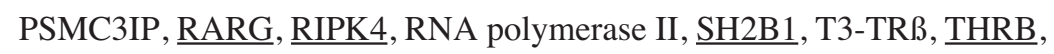
$\underline{\text { TIMP3 }}, \underline{\text { TRIM32 }}$

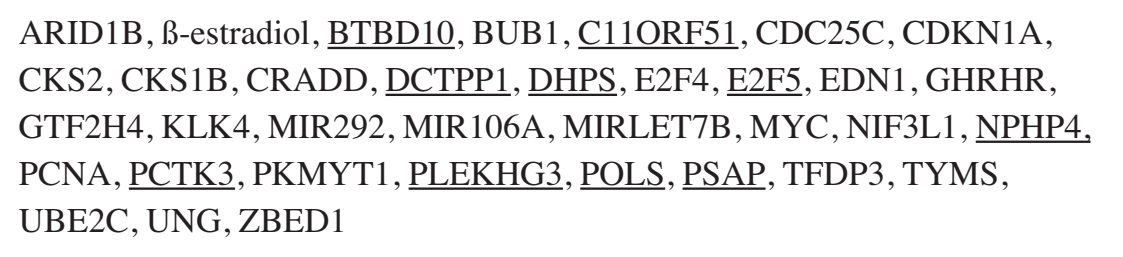

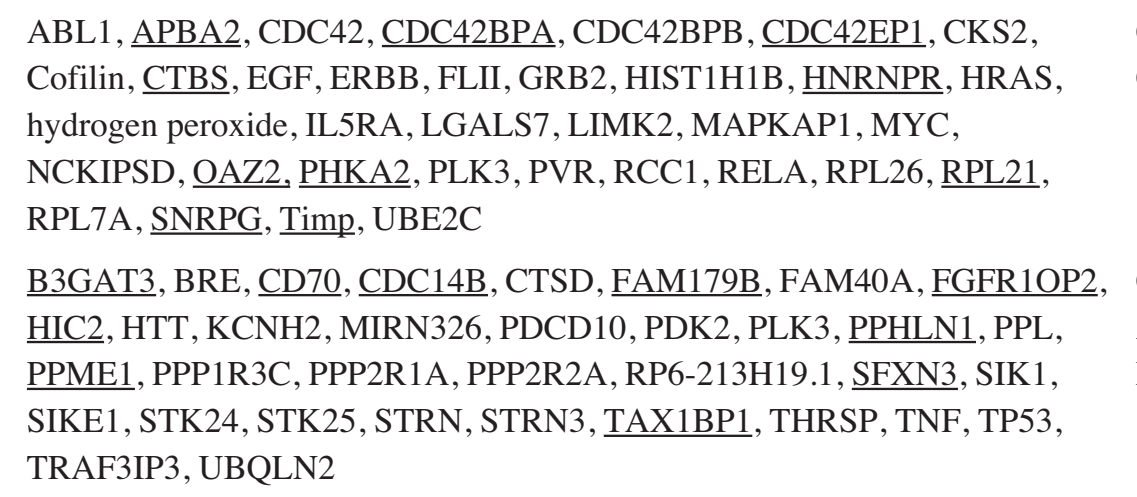
$\underline{\text { B3GAT3 }}$, BRE, $\underline{\text { CD70 }}, \underline{\text { CDC14B }}$, CTSD, FAM179B, FAM40A, FGFR1OP2, HIC2, HTT, KCNH2, MIRN326, PDCD10, PDK2, PLK3, PPHLN1, PPL, PPME1, PPP1R3C, PPP2R1A, PPP2R2A, RP6-213H19.1, SFXN3, SIK1, SIKE1, STK24, STK25, STRN, STRN3, TAX1BP1, THRSP, TNF, TP53, TRAF3IP3, UBQLN2
Cell cycle,
Cell signaling,
Connective tissue
development and function

Cell cycle,
Cell death

Cell death,

Amino acid metabolism, Molecular transport 

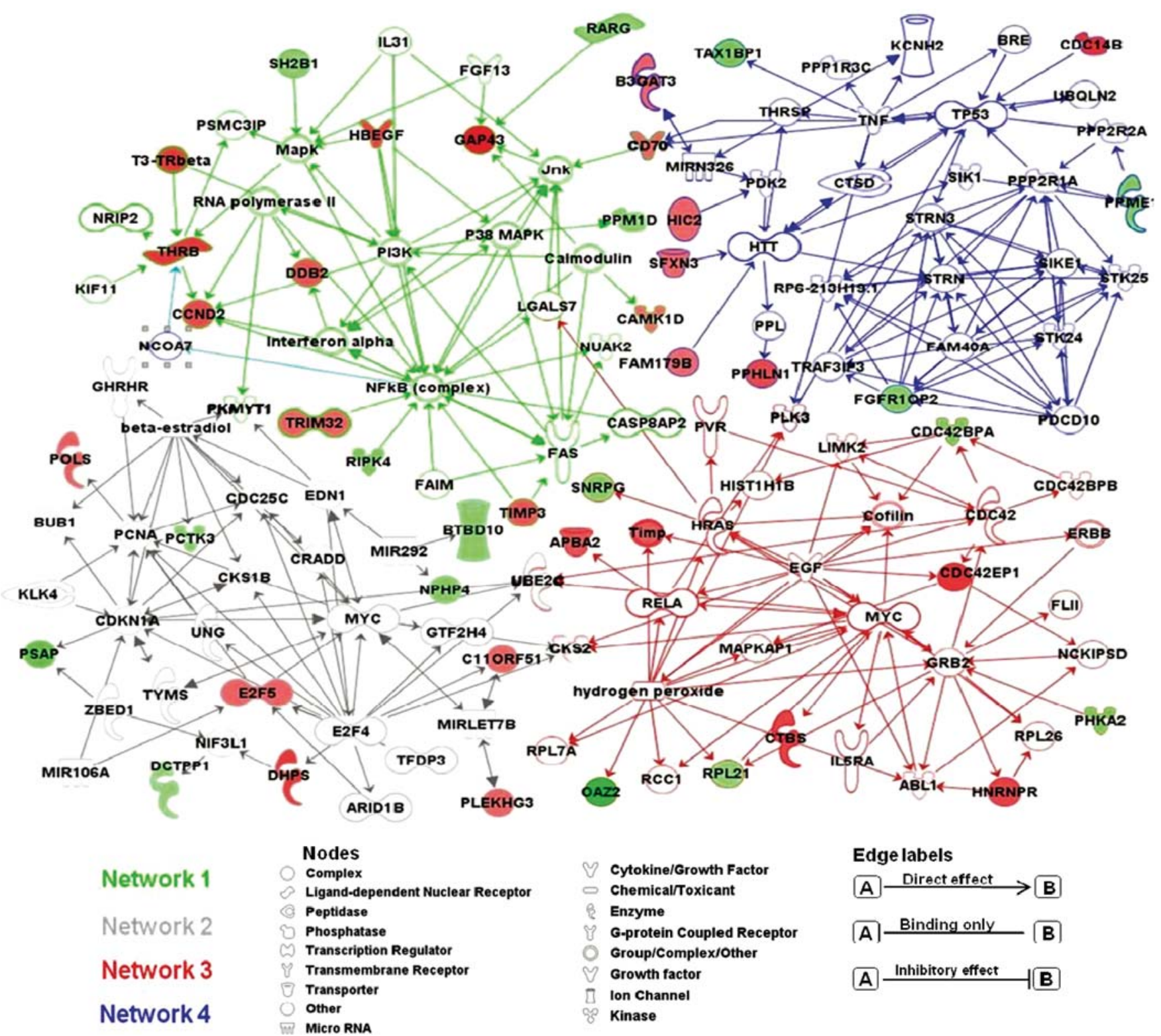

Edge labels

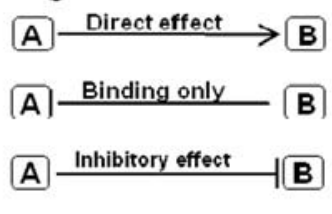

A] Binding only $B$

A Inhibitory effect

Figure 1. Interrelated networks of genes whose expression was modified after $\mathrm{C} 12$ irradiation. In total, four important networks of interrelated genes were identified. The four networks (green, network 1; orange, network 2; red, network 3; blue, network 4) were merged by overlapping genes (in bold). The degree of either upregulation (red) or downregulation (green) is reflected from the intensity of node colour.

measurement for each hybridization, which can be used for quality control and for reduction of technical variability.

Network and gene ontology analyses. The fluorescent data from all experiments were normalized and analyzed for differentially expressed genes by using the Genesis package (16). Genetic network and functional classification of differentially expressed genes were investigated by using the IPA software (Ingenuity Systems, Mountain View, CA), a webdelivered tool that enables the discovery, visualization, and exploration of molecular interaction networks in gene expression data (17).

Quantitative real-time PCR. Validation of the expression of selected candidate genes was performed using SYBR Green Mixtures (Abgene, Darmstadt) on MyiQ thermocycler (Bio-
Rad, Munich). Primer sequences used for candidate genes and glyseraldehyde-3-phosphate dehydrogenase (GAPDH) as an internal control are shown in Table I. Each reaction contained $12.5 \mu 1$ of $2 \mathrm{x}$ iQ SYBR Green mixes, $2.5 \mu 1$ of cDNA sample, and $70 \mathrm{nM}$ gene-specific primers in a final volume of $25 \mu 1$. All reactions were performed in triplicates. The PCR reaction was evaluated by melting curve analysis and the calculations for determining the relative level of gene expression were made using the cycle threshold $(\mathrm{Ct})$ method. The mean $\mathrm{Ct}$ values from triplicate measurements were used to calculate relative expression of the target genes with normalization to GAPDH used as internal control using the 2- $\Delta \Delta \mathrm{Ct}$ method.

Statistical analysis. The association between the transcriptional expression of the irradiated and unirradiated cells was analysed 
A.

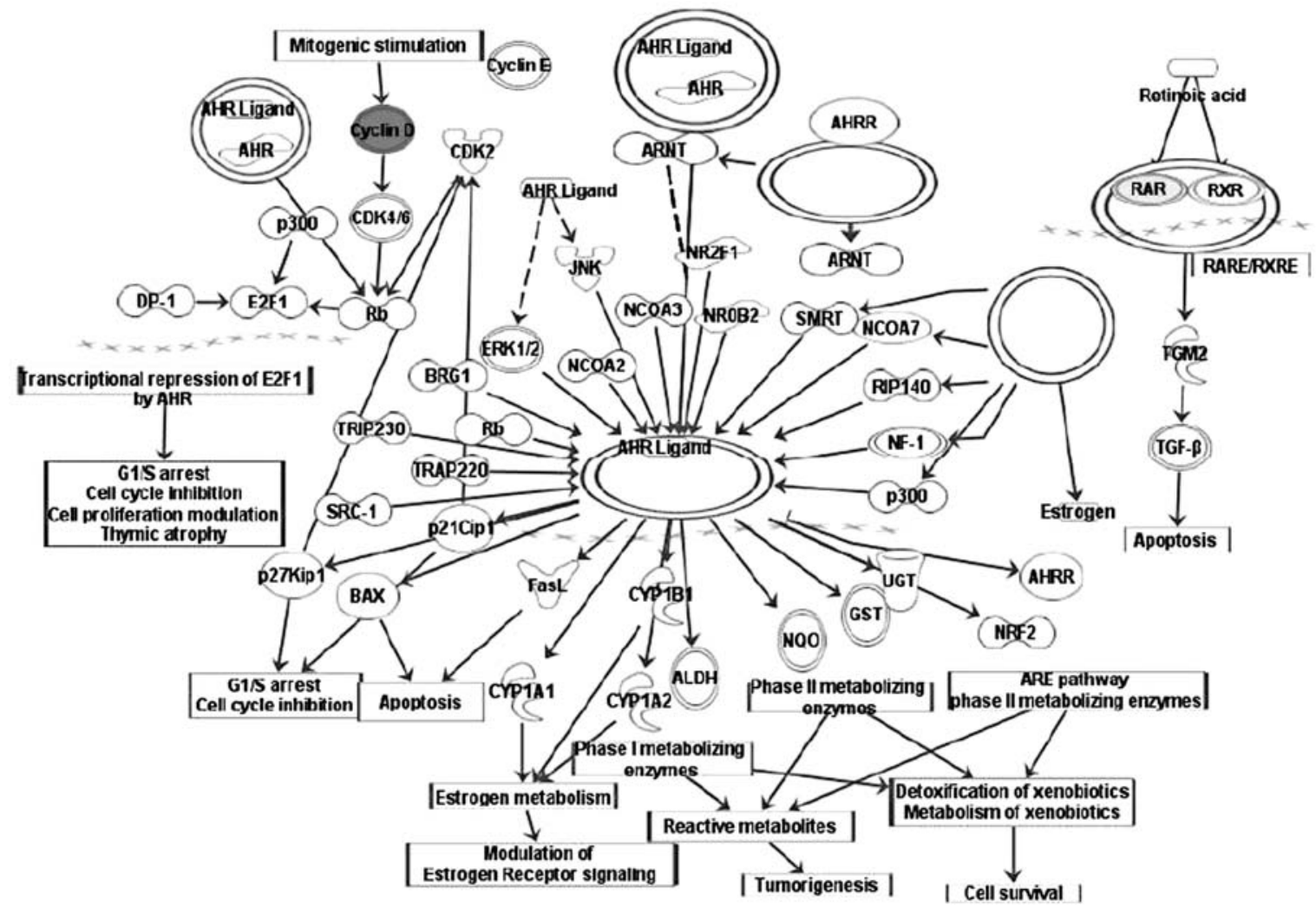

B.
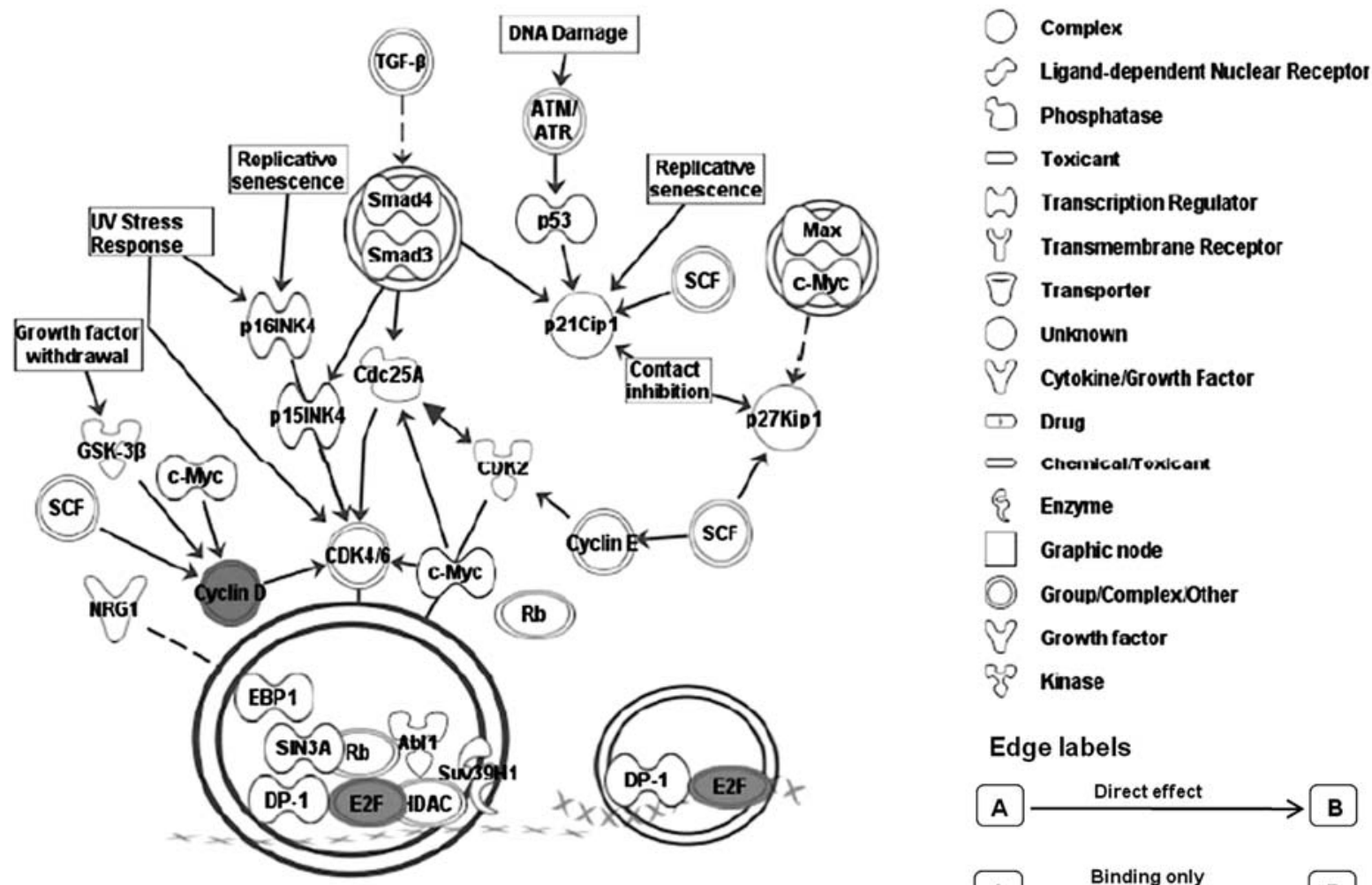

Edge labels

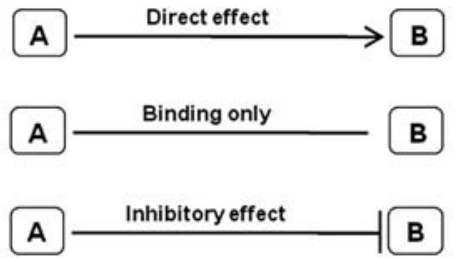

Figure 2. Important canonical pathways according to altered expression of genes after C12 irradiation. The AhR signaling (A) and the cell cycle: G1/S checkpoint regulation pathway (B) were on the top of the significant pathways list. Gray notes indicate upregulated genes. Genes which were not specified but integrated into the network through relationships are shown as white. For illustration purposes, the AhR pathway was simplified including only the genes with altered expression. 
Table III. Canonical pathways in carbon ion-irradiated genes.

\begin{tabular}{lc}
\hline Ingenuity canonical pathways & P-value \\
\hline Aryl hydrocarbon receptor signaling & 0.007762 \\
Cell cycle: G1/S checkpoint regulation & 0.012589 \\
p53 signaling & 0.030903 \\
Glioma signaling & 0.033884 \\
Pancreatic adenocarcinoma signaling & 0.038019 \\
Hereditary breast cancer signaling & 0.048978 \\
Lipid antigen presentation by CD1 & 0.049234 \\
\hline
\end{tabular}

using the Students t-test. The Fisher's test was used to analyze the significance of the canonical pathways and genetic networks identified by the IPA tool. A $p<0.05$ was considered significant.

\section{Results}

Identification of different expressed genes after X-ray and C12 irradiation. $\mathrm{C} 12$ have an increased RBE and previous reported RBE value of A549 cells was approximately 2.93 irradiated with highly energy carbon ions (18), we therefore used $1 / 3$ the physical doses of X-ray for doses of $\mathrm{C} 12$ beams to compare the expression profile of A549 cells at the biologically effective doses (BED).

We performed profiled gene expression and compared expression in cells at $4 \mathrm{~h}$ after $\mathrm{C} 12$ (2 Gy) and X-ray irradiation (6 Gy) by examining 11,800 transcripts. We aimed to identify genes which may be affected in the response to $\mathrm{C} 12$ ions, but not after X-ray irradiation in lung cancer cells. Micro-array analysis revealed a significant alteration in the expression of 49 genes (at least 2-fold) after C12 irradiation and not altered by X-rays, as compared with control unirradiated cells. Of these 49 differentially expressed genes identified, 29 and 20 genes were up- and down-regulated, respectively.

Network and gene ontology analyses. The genetic network and functional classification of the differentially expressed genes were executed using the IPA tool. In total, all of the 49 genes were mapped, network-eligible and classified into genetic networks. From the 49 genes, 43 genes were part of networks that shared at least one overlapping gene in common and were merged together. In our study, 4 merged networks were identified (Fig. 1). The IPA tool depicted important biological pathways associated with these 4 merged networks (Table II). Different molecular events directly relevant to cancer were identified i.e. cell cycle, cancer and cell death signaling, cell signaling (Table II).

The rest of the 6 genes which were altered by $\mathrm{C} 12$, but not by X-rays, were detected in separate networks which, in contrast to the 4 overlapping networks mentioned above, were not overlapping between them due to the lack of commonly-shared gene. These included i) cellular development: HPS1 (up-regulated), ii) molecular transport and metastasis: ABCC5 (up-regulated), SYDE1 (down-
Table IV. Irradiation-induced fold changes in selected genes after carbon ions and X-ray treatment.

\begin{tabular}{llcc}
\hline Gene sybol & \multicolumn{2}{c}{ Gene name } & \multicolumn{2}{c}{ Fold changes } \\
\cline { 3 - 4 } & & Carbon & X-ray \\
\hline CCND2 & Cyclin D2 & 2.35 & 1.26 \\
RARG & Retinoic acid receptor- $\gamma$ & 0.42 & 0.88 \\
E2F5 & E2F transcription factor F5 & 2.29 & 1.24 \\
CDC14B & CDC14B protein phosphatase & 2.84 & 1.43 \\
\hline
\end{tabular}

The differential expression in genes irradiated with carbon ions and $\mathrm{X}$-rays is depicted.

regulated), TSPAN17 (down-regulated), iii) cell morphology: C90RF75 (down-regulated) and iv) immune response: RNF219 (up-regulated).

Gene ontology analysis detected canonical pathways with known implications in cancer (Table III). Among these, statistically significant pathways such as aryl hydrocarbon receptor $(A h R)$ signaling $(\mathrm{p}=0.0077)$ and $\mathrm{G} 1 / \mathrm{S}$ cell cycle checkpoint ( $\mathrm{p}=0.012$ ) were identified (Fig. 2A and B; Table III). From the genes detected, CCND2 was involved in both pathways. The others included RARG and E2F5 (Fig. 2A). Four of the genes with altered expression after C12 irradiation, in microarray analysis, are shown on Table IV.

Validation of microarray data by real-time PCR. To validate the results of microarray experiments, 4 differentially expressed genes involved in the AhR signaling and cell cycle were verified by qRT-PCR using RNA isolated at $4 \mathrm{~h}$ after IR. We analyzed the same RNA used for the microarray experiment. The expression levels of selected genes were similar with microarray data at $4 \mathrm{~h}$ post-irradiation with $\mathrm{C} 12$, as compared with the control and are shown in Fig. $3(p<0.05)$. Only minor, non-significant changes were observed after X-ray irradiation, as compared with the unirradiated control group, validating our microarray data.

\section{Discussion}

Heavy ions such as $\mathrm{C} 12$ beams are characterized by higher RBE than X-rays and enhanced ionization density in the individual tracks of the heavy particles, where DNA damage becomes clustered and therefore more difficult to repair (7). In comparison to the low-LET proton and photon beams, carbons are of mixed LET with low LET in the entrance channel and high LET in the target volume and therefore DNA damage is restricted to the end of their range (19). Altogether, the superior biophysical and biological profile of carbons over conventional radiotherapy enables more precise dose localization for the therapy of anatomically complex and radioresistant malignancies, sparing the normal tissues from the severe side effects of conventional radiation (20).

Although a recent study demonstrated the ability of $\mathrm{C} 12$ to suppress the metastatic ability of lung cancer cells (21), to date, no detailed report on the gene expression profiles of lung 
CCND2

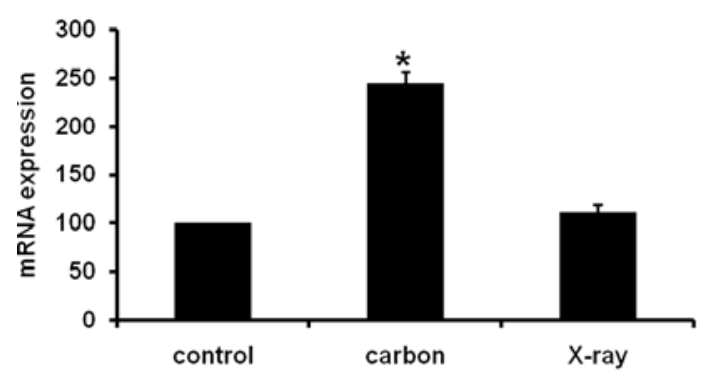

E2F5

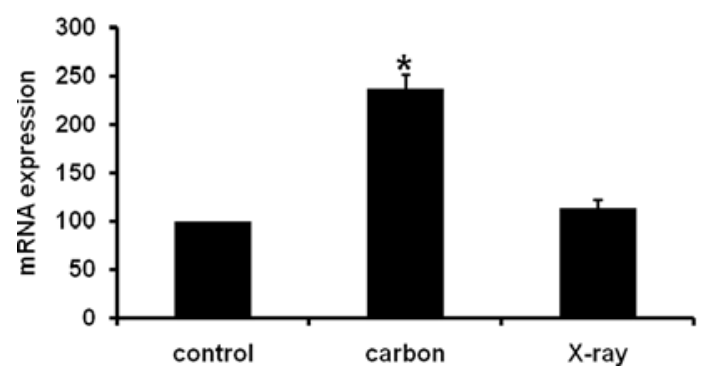

RARG

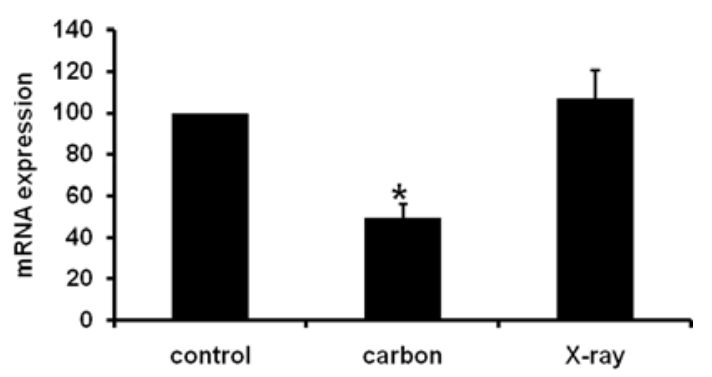

CDC14B

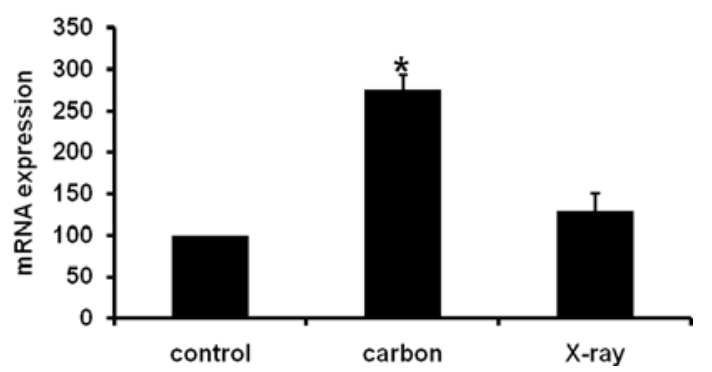

Figure 3. Validation of selected differently expressed genes in A549 cells at $4 \mathrm{~h}$ after carbon C12 and X-ray irradiation using qRT-PCR. The results of transcriptional expression were normalized to the values of GAPDH gene and then expressed as a percentage in comparison to the unirradiated, control cells ( 0 Gy). The significance in genetic expression changes after $\mathrm{C} 12$ was confirmed ( $<<0.05$, Student's t-test). No major change was observed after treatment with $\mathrm{X}$-rays. Data are expressed as mean $\pm \mathrm{SD}$.

cancer cells after C12 irradiation has been published. Our primary purpose was to detect genes specifically altered by C12 irradiation but not X-rays, which could account for the increased efficacy of heavy ions, as compared to conventional radiation. We irradiated cells with $\mathrm{C} 12$ ions and X-rays using BED. We employed a gene chip to analyze gene expression changes after C12 irradiation in A549 human lung adenocarcinoma cells. We identified 49 mapped genes, whereby 29 were overexpressed while 20 genes were downregulated $4 \mathrm{~h}$ post-irradiation with $\mathrm{C} 12$ and not altered by X-rays. Four major networks were detected and merged via overlapping genes. Network 1, 2 and 3 were closely associated with the cell cycle while network 3 and 4 included genes involved in the cell death machinery signaling.

The genetic mechanisms responsible for the increased effectiveness of heavy ions are currently under investigation but only few exist to date. Higo et al (10) performed a microarray study in oral squamous cells carcinoma cells (OSCCs) after C12 irradiation and focused specifically on the genes which showed no change in their expression after X-ray irradiation, similarly to our study. A series of 98 genes were modified upon C12 irradiation, among which SPHK1, a secondary messenger in cellular proliferation and survival. In a similar study from the same group, 84 genes were found to be modulated while the transforming growth factor $\beta$-signaling pathway (TGF- $\beta$ ) and cell cycle: G1/S checkpoint regulation pathway were those most affected from C12 in OSCCs (11). Matsumoto et al (12) detected transcriptional changes in several genes involved in the regulation of cell cycle and G2/M arrest. C12 induced upregulation of stress-responsive and cell-communication genes common to different tumor models in vivo, which could explain their efficacy (22).
Moreover, we investigated the canonical pathways in response to $\mathrm{C} 12$ irradiation. The study revealed that the AhR signaling and the cell cycle G1/S DNA damage checkpoint regulation were highly significant, detected on the top of the list. The AhR signaling has been previously implicated in the pathogenesis of lung cancer $(23,24)$. One gene (CCND2) was upregulated and one (RARG) was downregulated in this pathway. The family of retinoic acid receptors (RAR) is dysregulated in lung cancer and repression of RAR- $\beta$ is often observed in lung carcinogenesis $(25,26)$. Although RARG has been implied in tumor development (27), and retinoic acidinduced cell cycle arrest and apoptosis, its functions are not well characterized while its overexpression does not confer resistance to chemotherapy $(28,29)$. The downregulation of RARG found in our study might have an impact on the regulation of cell cycle and apoptosis induced by carbon irradiation. More studies on the function of RARG will clarify this issue.

The importance of cell cycle in preservation of genomic stability and response to radiation-induced damage has been thoroughly investigated (30). Irradiation causes delays in the movement through the different phases of cell cycle while cells found in S- and plateau-phase are more radioresistant than cells in G2- or mitotic phase $(30,31)$. Radioresistance to conventional radiotherapy can be overcome by $\mathrm{C} 12$ which can induce cell cycle arrest much more potently than low-LET beams $(32,33)$. For increasing LET values, a general decrease of the variation in sensitivity, according to the phase, has been observed (34). In our study, CCND2 and E2F5 were the two genes associated with the cell cyle: G1/S checkpoint regulation. CCND2 forms a complex with and functions as a regulatory subunit of $\mathrm{CDK} 4$ or CDK6, whose activity is required for cell cycle $\mathrm{G} 1 / \mathrm{S}$ transition by interacting with the 
tumor suppressor protein Rb. Upregulation of CCND2 can decrease proliferation and growth of tumors both in vitro and in vivo $(35,36)$. Interestingly, overexpression of cyclin D2 protein efficiently inhibited cell cycle progression and DNA synthesis in primary human and established murine fibroblasts indicating that cyclin D2 can induce a non-proliferative state, possibly through sequestration of the CDK2 catalytic subunit (37). Moreover, E2F activity is tightly controlled by RB and deregulated expression or activity of most members of the E2F family has been detected in many human cancers (38). E2F5, similarly to E2F4, is necessary for pocket protein-mediated G1 arrest of cycling cells (39). Another gene of interest with an important role in cell cycle regulation found upregulated by $\mathrm{C} 12$ was $\mathrm{CDC} 14 \mathrm{~B}$ protein phosphatase. Cdc14B delays cell cycle progression from mitosis to $\mathrm{S}$ phase in an Skp2dependent manner (40), while the Cdc14B-Cdh1-Plk axis inhibits Cdk1 and prevents entry into mitosis. The upregulation, therefore, of CCND2, E2F5 and CDC14B observed in our study could have played an important role in cell cycle response and survival to irradiation with $\mathrm{C} 12$ in A549 cells. Notably, overexpression of different members from both cyclin D and E2Fs family after irradiation with $\mathrm{C} 12$ has been detected before $(11,22)$.

In conclusion, we aimed to identify genes whose expression was modified only by $\mathrm{C} 12$ and not by X-rays. In total, 49 mapped, network-eligible genes with known functions were characterized by gene ontology. Among others, two canonical pathways (aryl hydrocarbon receptor signalling and G1/S checkpoint machinery) were significant. The differential expression of key genes such as RARG, CCND1, E2F5 and $\mathrm{CDC} 14 \mathrm{~B}$ could be important in distinguishing the genetic signature and response of lung cancer cells to C12 therapy. Future studies are needed to examine these genes in detail and will provide insights into their role in lung cancer cells exposed to $\mathrm{C} 12$.

\section{Acknowledgements}

We are grateful to Dr Claudia Fournier, Dr Gisela TaucherScholz and Professor Gerhardt Kraft from the Department of Biophysics, Gesellschaft für Schwerionenforschung (GSI) Darmstadt, Germany, for their expertise and guidance in radiating tumor cells with carbon ions at the UNILAC facility at GSI. We declare that we have no conflict of interest in relation to the publication of this manuscript.

\section{References}

1. Jemal A, Siegel R, Ward E, Hao Y, Xu J and Thun MJ: Cancer statistics. CA Cancer J Clin 59: 225-249, 2009.

2. Klautke G, Sauer R and Fietkau R: Combined treatment modality in small cell lung cancer: the impact of radiotherapy on survival. Strahlenther Onkol 184: 61-66, 2008.

3. Mirri MA, Arcangeli G, Benassi M, d'Angelo A, Pinzi V, Caterino M, Rinaldi M, Ceribelli A and Strigari L: Hypofractionated Conformal Radiotherapy (HCRT) for primary and metastatic lung cancers with small dimension: efficacy and toxicity. Strahlenther Onkol 185: 27-33, 2009.

4. Hocht S, Heide J, Bischoff R, Grundel O and Carstens D: Postoperative irradiation in non-small cell lung cancer. Front Radiat Ther Oncol 42: 145-149, 2010

5. Miyamoto T, Baba M, Yamamoto N, Koto M, Sugawara T, Yashiro T, Kadono K, Ezawa H, Tsujii H, Mizoe JE, Yoshikawa K, Kandatsu S, Fujisawa T; Working Group for
Lung Cancer: Curative treatment of Stage I non-small-cell lung cancer with carbon ion beams using a hypofractionated regimen. Int J Radiat Oncol Biol Phys 67: 750-758, 2007.

6. Miyamoto T, Baba M, Sugane T, Nakajima M, Yashiro T, Kagei K, Hirasawa N, Sugawara T, Yamamoto N, Koto M, Ezawa H, Kadono K, Tsujii H, Mizoe JE, Yoshikawa K, Kandatsu S, Fujisawa T; Working Group for Lung Cancer: Carbon ion radiotherapy for stage I non-small cell lung cancer using a regimen of four fractions during 1 week. $\mathrm{J}$ Thorac Oncol 2: 916-926, 2007

7. Fokas E, Kraft G, An H and Engenhart-Cabillic R: Ion beam radiobiology and cancer: time to update ourselves. Biochim Biophys Acta 1796: 216-229, 2009.

8. Grutters JP, Kessels AG, Pijls-Johannesma M, De Ruysscher D, Joore MA and Lambin P: Comparison of the effectiveness of radiotherapy with photons, protons and carbon-ions for non-small cell lung cancer: a meta-analysis. Radiother Oncol 95: 32-40, 2010.

9. Voduc D, Kenney C and Nielsen TO: Tissue microarrays in clinical oncology. Semin Radiat Oncol 18: 89-97, 2008.

10. Higo M, Uzawa K, Kawata T, Kato Y, Kouzu Y, Yamamoto N, Shibahara T, Mizoe JE, Ito H, Tsujii $\mathrm{H}$ and Tanzawa $\mathrm{H}$ : Enhancement of SPHK1 in vitro by carbon ion irradiation in oral squamous cell carcinoma. Int J Radiat Oncol Biol Phys 65: 867-875, 2006.

11. Fushimi K, Uzawa K, Ishigami T, Yamamoto N, Kawata T, Shibahara T, Ito H, Mizoe JE, Tsujii H and Tanzawa H: Susceptible genes and molecular pathways related to heavy ion irradiation in oral squamous cell carcinoma cells. Radiother Oncol 89: 237-244, 2008.

12. Matsumoto $Y$, Iwakawa M, Furusawa $Y$, Ishikawa K, Aoki M, Imadome K, Matsumoto I, Tsujii H, Ando K and Imai T: Gene expression analysis in human malignant melanoma cell lines exposed to carbon beams. Int J Radiat Biol 84: 299-314, 2008.

13. Tamaki T, Iwakawa M, Ohno T, Imadome K, Nakawatari M, Sakai M, Tsujii H, Nakano T and Imai T: Application of carbonion beams or gamma-rays on primary tumors does not change the expression profiles of metastatic tumors in an in vivo murine model. Int J Radiat Oncol Biol Phys 74: 210-218, 2009.

14. Jakob B, Scholz M and Taucher-Scholz G: Characterization of CDKN1A (p21) binding to sites of heavy-ion-induced damage: colocalization with proteins involved in DNA repair. Int J Radiat Biol 78: 75-88, 2002.

15. Berwanger B, Hartmann O, Bergmann E, Bernard S, Nielsen D, Krause M, Kartal A, Flynn D, Wiedemeyer R, Schwab M, Schäfer H, Christiansen $H$ and Eilers M: Loss of a FYNregulated differentiation and growth arrest pathway in advanced stage neuroblastoma. Cancer Cell 2: 377-386, 2002.

16. Sturn A, Quackenbush J and Trajanoski Z: Genesis: cluster analysis of microarray data. Bioinformatics 18: 207-208, 2002.

17. Calvano SE, Xiao W, Richards DR, Felciano RM, Baker HV, Cho RJ, Chen RO, Brownstein BH, Cobb JP, Tschoeke SK, Miller-Graziano C, Moldawer LL, Mindrinos MN, Davis RW, Tompkins RG, Lowry SF; Inflamm and Host Response to Injury Large Scale Collab. Res. Program: A network-based analysis of systemic inflammation in humans. Nature 437: 1032-1037, 2005.

18. Elsässer T, Krämer M and Scholz M: Accuracy of the local effect model for the prediction of biologic effects of carbon ion beams in vitro and in vivo. Int J Radiat Oncol Biol Phys 71: 866-872, 2008.

19. Weber U and Kraft G: Comparison of carbon ions versus protons. Cancer J 15: 325-332, 2009.

20. Schulz-Ertner D and Tsujii H: Particle radiation therapy using proton and heavier ion beams. J Clin Oncol 25: 953-964, 2007.

21. Akino Y, Teshima T, Kihara A, Kodera-Suzumoto Y, Inaoka M, Higashiyama S, Furusawa Y and Matsuura N: Carbon-ion beam irradiation effectively suppresses migration and invasion of human non-small-cell lung cancer cells. Int J Radiat Oncol Biol Phys 75: 475-481, 2009.

22. Imadome K, Iwakawa M, Nojiri K, Tamaki T, Sakai M, Nakawatari M, Moritake T, Yanagisawa M, Nakamura E, Tsujii $\mathrm{H}$ and Imai T: Upregulation of stress-response genes with cell cycle arrest induced by carbon ion irradiation in multiple murine tumors models. Cancer Biol Ther 7: 208-217, 2008.

23. Chang JT, Chang H, Chen PH, Lin SL and Lin P: Requirement of aryl hydrocarbon receptor overexpression for CYP1B1 upregulation and cell growth in human lung adenocarcinomas. Clin Cancer Res 13: 38-45, 2007. 
24. Kim JH, Kim H, Lee KY, Kang JW, Lee KH, Park SY, Yoon HI, Jheon SH, Sung SW and Hong YC: Aryl hydrocarbon receptor gene polymorphisms affect lung cancer risk. Lung Cancer 56: 9-15, 2007.

25. Lu C, Soria JC, Tang X, Xu XC, Wang L, Mao L, Lotan R, Kemp B, Bekele BN, Feng L, Hong WK and Khuri FR: Prognostic factors in resected stage I non-small-cell lung cancer: a multivariate analysis of six molecular markers. J Clin Oncol 22: 4575-4583, 2004.

26. Petty WJ, Li N, Biddle A, Bounds R, Nitkin C, Ma Y, Dragnev KH, Freemantle SJ and Dmitrovsky E: A novel retinoic acid receptor beta isoform and retinoid resistance in lung carcinogenesis. J Natl Cancer Inst 97: 1645-1651, 2005.

27. Brabender J, Metzger R, Salonga D, Danenberg KD, Danenberg PV, Hölscher AH and Schneider PM: Comprehensive expression analysis of retinoic acid receptors and retinoid X receptors in non-small cell lung cancer: implications for tumor development and prognosis. Carcinogenesis 26: 525-530, 2005.

28. Kumar A, Soprano DR and Parekh HK: Cross-resistance to the synthetic retinoid CD437 in a paclitaxel-resistant human ovarian carcinoma cell line is independent of the overexpression of retinoic acid receptor-gamma. Cancer Res 61: 7552-7555, 2001.

29. Makkonen KM, Malinen M, Ropponen A, Väisänen S and Carlberg C: Cell cycle regulatory effects of retinoic Acid and forskolin are mediated by the cyclin C gene. J Mol Biol 393: 261-271, 2009

30. Kastan MB and Bartek J: Cell-cycle checkpoints and cancer. Nature 432: 316-323, 2004

31. Pawlik TM and Keyomarsi K: Role of cell cycle in mediating sensitivity to radiotherapy. Int J Radiat Oncol Biol Phys 59: 928-942, 2004

32. Blakely E, Chang P, Lommel L, Bjornstad K, Dixon M, Tobias C, Kumar K and Blakely WF: Cell-cycle radiation response: role of intracellular factors. Adv Space Res 9: 177-186, 1989.
33. Fournier C, Winter M, Zahnreich S, Nasonova E, Melnikova L and Ritter S: Interrelation amongst differentiation, senescence and genetic instability in long-term cultures of fibroblasts exposed to different radiation qualities. Radiother Oncol 83: 277-282, 2007.

34. Fournier $\mathrm{C}$ and Taucher-Scholz G: Radiation induced cell cycle arrest: an overview of specific effects following high-LET exposure. Radiother Oncol 73 (Suppl. 2): S119-S122, 2004.

35. Fritz MD, Mirnics ZK, Nylander KD and Schor NF: p75NTR enhances PC12 cell tumor growth by a non-receptor mechanism involving downregulation of cyclin D2. Exp Cell Res 312: 3287-3297, 2006

36. Kobayashi T, Nakamura E, Shimizu Y, Terada N, Maeno A, Kobori G, Kamba T, Kamoto T, Ogawa $\mathrm{O}$ and Inoue T: Restoration of cyclin D2 has an inhibitory potential on the proliferation of LNCaP cells. Biochem Biophys Res Commun 387: 196-201, 2009.

37. Meyyappan M, Wong H, Hull C and Riabowol KT: Increased expression of cyclin D2 during multiple states of growth arrest in primary and established cells. Mol Cell Biol 18: 3163-3172, 1998.

38. Chen HZ, Tsai SY and Leone G: Emerging roles of E2Fs in cancer: an exit from cell cycle control. Nat Rev Cancer 9: 785-797, 2009.

39. Gaubatz S, Lindeman GJ, Ishida S, Jakoi L, Nevins JR, Livingston DM and Rempel RE: E2F4 and E2F5 play an essential role in pocket protein-mediated G1 control. Mol Cell 6: 729-735, 2000

40. Rodier G, Coulombe P, Tanguay PL, Boutonnet C and Meloche S: Phosphorylation of Skp2 regulated by CDK2 and Cdc14B protects it from degradation by APC(Cdh1) in G1 phase. EMBO J 27: 679-691, 2008. 